\title{
POLA PENGGUNAAN OBAT PADA PASIEN GASTROESOPHAGEAL REFLUX DISEASE (GERD) DI SALAH SATU RUMAH SAKIT DI BANDUNG
}

\author{
Linda P. Suherman*, Robby Ramdani, Vina Septiani, Wiwik Indrayani, Alfi Nurul \\ Islamiyah, Putri Khotimah Hasyim \\ Fakultas Farmasi, Universitas Jenderal Achmad Yani \\ Email : lindapsuherman@gmail.com \\ Received: 28/06/2021, Revised: 07/08/2021, Accepted: 17/08/2021, Published: 18/08/2021
}

\begin{abstract}
ABSTRAK
Gastroesophageal Reflux Disease (GERD) adalah salah satu bentuk gangguan pencernaan dimana $\mathrm{HCl}$ naik dari lambung ke esofagus, sehingga menimbulkan gejala klinis dan komplikasi yang menurunkan kualitas hidup seseorang. Di Indonesia prevalensi GERD sudah mencapai 27,4\%. Bahaya GERD jika tidak ditangani akan mengganggu kerja sistem pencernaan dan meningkatkan resiko kanker esofagus. Sehingga diperlukan pengobatan yang tepat. Tujuan dilakukannya penelitian ini adalah untuk mengetahui gambaran profil dan rasionalitas penggunaan obat pada pasien GERD di salah satu Rumah Sakit di Bandung periode Januari - Desember 2019. Penelitian ini merupakan penelitian deskriptif non eksperimental menggunakan metode purposive sampling. Pengumpulan data diperoleh dari 41 rekam medik pasien GERD di instalasi rawat inap yang memenuhi kriteria inklusi secara retrospektif. Berdasarkan hasil penelitian, dapat disimpulkan bahwa penderita GERD sebagian besar adalah perempuan sebesar 53,66\%, berdasarkan usia paling banyak pada usia 26-35 tahun sebesar 29,26\%. Obat GERD yang paling banyak digunakan adalah kombinasi 2 obat Pantoprazol + Sukralfat sebesar 58,54\%. Penggunaan obat pada pasien GERD sudah rasional dengan persentase penggunaan obat berdasarkan tepat obat $100 \%$, tepat dosis $97,56 \%$, tepat interval waktu pemberian $97,56 \%$ dan tepat rute pemberian $100 \%$.
\end{abstract}

Kata kunci : GERD, pola penggunaan obat, rasionalitas

\section{ABSTRACT}

GERD (Gastroesophageal Reflux Disease) was a condition in which HCL refluxes from the stomach to the esophagus, causing symptoms and complications that reduce a person's quality of life. Based on research the prevalence of GERD in Indonesia has reached 27,4\%. GERD disease if left unchecked will damage the digestive system and increase the risk of cancer release. The purpose of this study was to determine the description and rationality of drug use in GERD patients at one of Hospital in Bandung the period of January-December 2019. This research is a non-experimental descriptive research using purposive sampling method. Data collection was obtained from 41 medical records of GERD inpatients who met the inclusion criteria retrospectively. Based on the findings of the study, it can be concluded that GERD patients are more commonly found in female patients (53,66 percent), with the most common age group being 26-35 years (29,26 percent). The most used GERD drug is a combination of two drugs Pantoprazole + Sucralfate (58,54 percent). The use of drugs in GERD patients was rational with 
the percentage of drug use based on a fully appropriate drug selection and route of administration, 97,56\% appropriate dose, and 97,56\% appropriate the time interval.

Keywords: GERD, drug use pattern,rationality

\section{PENDAHULUAN}

Penyakit pencernaan di mana asam lambung naik ke esophagus sehingga menciptakan gejala klinis dan dapat menurunkan kualitas hidup seseorang disebut GERD. Pola makan, genetik, NSAID (Nonsteroidal AntiInflammatory Drugs), merokok, obesitas, faktor perusak lambung dan faktor pelindung lambung merupakan faktor-faktor yang dapat menyebabkan GERD. Sekresi bikarbonat, sekresi mukus, regenerasi epitel dan aliran darah mukosa merupakan faktor pelindung lambung. Faktor perusak lambung terdiri dari $\mathrm{HCl}$ lambung dan zat yang dapat menyebabkan GERD. Masalah GERD disebabkan oleh kurangnya keseimbangan faktor pelindung dan faktor perusak pada organ lambung menyebabkan masalah GERD. Diharapkan dengan menghindari faktor berbahaya seperti kopi, NSAID dan makanan pedas, GERD tidak terulang kembali. (Ndraha dkk., 2016)

Di Amerika Utara sebesar 18,1\% $27,8 \%$ orang menderita GERD, dibandingkan dengan $8,8 \%-25,9 \%$ di Eropa. Di Asia Timur prevalensi GERD berkisar 2,5\% - 7,8\%, 11,6\% di Australia, dan 23,0\% di Amerika Selatan (El-Serag dkk., 2014). Di Indonesia Prevalensi GERD sudah mencapai 27,4\% (Syam dkk., 2016). Berdasarkan temuan penelitian lain, prevalensi GERD di Rumah Sakit rujukan primer di Jakarta adalah 49\% (Darnindro dkk., 2018). Penyakit GERD dapat disebabkan oleh gaya hidup yang tidak sehat atau faktor resiko seperti penggunaan obatobatan seperti antikolinergik, teofilin, beta adrenergik, calcium-channel blocker dan nitrat kemungkinan merupakan penyebab penyakit GERD (Bestari, 2011).

Obat-obatan, makanan berlemak, kafein, alkohol, merokok, hormon dan obesitas adalah beberapa faktor penyebab GERD. GERD umumnya dianggap sebagai penyakit ringan, tetapi dapat menyebabkan kekambuhan dan kematian jika tidak ditangani. Jika tidak diobati, asam lambung dapat menyebabkan luka pada ulkus, mengakibatkan muntah darah (Saputera, M. D., \& Budianto, W., 2017).

Jika tidak ditangani, bahaya GERD dapat mengganggu fungsi sistem pencernaan dan meningkatkan risiko kanker esofagus sehingga memerlukan ketepatan pengobatan (Ndraha dkk., 2016). Untuk mengurangi tingkat GERD yang terus meningkat serta untuk meningkatkan kualitas hidup pasien maka perlu dilakukan penelitian mengenai 
pola penggunaan obat pada pasien GERD yang ditinjau dari kriteria tepat obat, tepat dosis, tepat interval waktu pemberian, dan tepat rute pemberian. Hal tersebut dilakukan agar terapi pengobatan yang diperoleh bisa tepat sehingga keberhasilan dalam pengobatan dapat dicapai, serta dapat mengurangi tingkat kekambuhan penyakit dan efek samping yang tidak diharapkan.

Dari hasil penelitian Friyanto, D. dan Lestari, S. (2019) menunjukkan terdapat 68 pasien GERD di RSUD Karawang dan persentase pasien perempuan lebih tinggi yaitu sebesar 51,5\%. Kerasionalan terapi pada pasien GERD di RSUD Karawang menggunakan tiga literatur yaitu Konsensus GERD di Indonesia edisi tahun 2013, British National Formulary edition 70, dan Pharmacotherapy Handbook. Hasil analisis menunjukkan rata-rata $64 \%$ tepat dosis, $59,3 \%$ tepat obat, $80,4 \%$ tepat indikasi dan $89,7 \%$ tepat pasien (Friyanto, D. dan Lestari, S., 2019).

Dari hasil penelitian Rahman A.A., Maulidina, W., dan Kosasih D., (2018) menunjukan bahwa pasien GERD paling tinggi ditemukan pada perempuan $(66,3 \%)$ dengan usia rata-rata 41-60 tahun $(44,2 \%)$ dan persentase pasien tidak memiliki riwayat penyakit berisiko sebesar 82,6\%. Lansoprazol merupakan obat GERD terbanyak yang diberikan (37,9\%) dengan dosis $30 \mathrm{mg} / \mathrm{hari}(37,9 \%)$. Lama pemberian pada terapi awal rata-rata selama 1-14 hari $(62,6 \%)$ dan banyak diberikan sebelum makan, hal ini di dasarkan pada aturan pakai obat pada terapi farmakologi GERD (Rahman A.A., Maulidina, W., dan Kosasih D., 2018)

Dari hasil penelitian Patala, R., dkk. (2021) menunjukkan bahwa persentase penggunaan obat pada.pasien GERD di Instalasi Rawat Inap RSU Anutapura Palu dengan hasil tepat dosis sebesar $100 \%$, tepat obat 96, $97 \%$ dan tepat indikasi sebesar 96,97 \%. Berdasarkan hal tersebut, maka penggunaan obat sudah rasional. (Patala, R., dkk., 2021).

Bandung merupakan salah satu kota besar di Indonesia dengan jumlah penduduk yang besar. Penelitian tentang pola penggunaan obat GERD di Bandung belum di temukan. Oleh karena itu, tujuan penelitian ini adalah untuk mengetahui gambaran profil dan rasionalitas penggunaan obat pada pasien GERD di salah satu Rumah Sakit di Bandung.

\section{METODE PENELITIAN}

\section{Jalannya Penelitian}

1. Jenis dan Rancangan Penelitian 
Penelitian ini merupakan penelitian deskriptif non eksperimental menggunakan metode purposive sampling. Pengumpulan data diperoleh dari 41 rekam medik pasien GERD di instalasi rawat inap yang memenuhi kriteria inklusi secara retrospektif. (Rahman A.A., Maulidina, W., dan Kosasih D., 2018). Penilaian rasionalitas penggunaan obat mengacu pada pedoman Kementrian Kesehatan RI (Kemenkes RI, 2011).

\section{Definisi Operasional}

Analisis penggunaan obat GERD yang rasional meliputi kriteria:

a. Tepat Obat

Obat yang dipilih harus memiliki efek terapeutik yang sesuai dengan indikasi penyakit.

b. Tepat Dosis

Jumlah obat diberikan kepada pasien dengan tepat, dimana dosisnya berada dalam kisaran dosis terapeutik dan disesuaikan dengan usia dan kondisi pasien.

c. Tepat Rute Pemberian

Rute pemberian yang dipilih harus sesuai dengan obat yang diberikan dan kondisi pasien.

d. Tepat Interval Waktu Pemberian

Interval waktu pemberian harus disesuaikan dengan obat yang diberikan dan kondisi pasien. (Kemenkes RI., 2011)
3. Populasi dan Sampel Penelitian

Berdasarkan Kriteria Inklusi dan Eksklusi. Kriteria inklusi adalah:

a. Rekam medik pasien di atas 18 tahun dengan diagnosis GERD tanpa penyakit penyerta yang dirawat dari bulan Januari sampai dengan Desember 2019.

b. Rekam medik pasien di atas 18 tahun dengan diagnosis GERD mendapatkan obat GERD.

Sedangkan kriteria eksklusi adalah:

a. Rekam medik pasien di atas 18 tahun yang dirawat dari bulan Januari sampai dengan Desember 2019 yang mendapatkan obat GERD dengan diagnosis non-Penyakit GERD.

b. Rekam medik pasien di atas 18 tahun dengan diagnosis GERD dan tidak mendapatkan obat GERD.

4. Permohonan Surat

Dilakukan pengurusan surat izin penelitian kepada Direktur Rumah Sakit dan ethical clearance melalui Ketua Komisi Etik Penelitian Universitas Padjajaran Bandung, sebelum melakukan penelitian.

5. Teknik pengambilan Data

Teknik pengumpulan data yang digunakan berupa catatan lembar data rekam medik yang memuat pola pengobatan pada pasien yang didiagnosis GERD di salah satu 
Rumah Sakit di Bandung periode Januari hingga Desember 2019.

\section{Teknik Analisis Data}

Di salah satu Rumah Sakit di Bandung, Data penelitian akan diolah dengan menggunakan analisa data untuk mendapatkan hasil analisis tentang pola penggunaan obat pada pasien GERD, yang meliputi :

a. Analisis Kuantitatif

Dilakukan analisis terhadap pola penggunaan obat GERD dengan melihat data pasien berdasarkan parameter jenis kelamin pasien, usia pasien, jenis dan penggolongan obat.

b. Analisis Kualitatif

Dilakukan analisis terhadap ketepatan penggunaan obat yang meliputi tepat obat, tepat dosis, tepat interval waktu pemberian, dan tepat rute pemberian.

\section{HASIL DAN PEMBAHASAN}

Setelah dilakukan penelitian diperoleh hasil sebagai berikut:

1. Analisis Kuantitatif

a. Deskripsi Pasien GERD Berdasarkan Jenis Kelamin

Dari 41 kasus yang di ambil dari data rekam medik pasien, jumlah pasien laki-laki sebanyak 19 pasien sedangkan perempuan sebanyak 22 pasien.
Tabel 1. Data Pasien GERD Berdasarkan Jenis Kelamin

\begin{tabular}{cccc}
\hline No. & $\begin{array}{c}\text { Jenis } \\
\text { Kelamin }\end{array}$ & $\begin{array}{c}\text { Jumlah } \\
\text { Pasien }\end{array}$ & $\begin{array}{c}\text { Persentase } \\
(\mathbf{n = 4 1})\end{array}$ \\
\hline 1 & Laki - laki & 19 & $46,34 \%$ \\
2 & Perempuan & 22 & $53,66 \%$ \\
\hline & Total & 41 & $100 \%$
\end{tabular}

b. Deskripsi Pasien GERD Berdasarkan Rentang Usia

Klasifikasi usia pasien pada penelitian ini dibagi menjadi 6 kelompok, yaitu 18 sampai dengan 25 tahun, 26 sampai dengan 35 tahun, 36 sampai dengan 45 tahun, 46 sampai dengan 55 tahun, 56 sampai dengan 65 tahun dan usia diatas 65 tahun.

Tabel 2. Data Pasien GERD Berdasarkan Usia

\begin{tabular}{cccc}
\hline No. & $\begin{array}{c}\text { Rentang } \\
\text { Usia }\end{array}$ & $\begin{array}{c}\text { Jumlah } \\
\text { Pasien }\end{array}$ & $\begin{array}{c}\text { Persentase } \\
(\mathbf{n}=41)\end{array}$ \\
\hline 1 & $18-25$ & 6 & $14,63 \%$ \\
2 & $26-35$ & 12 & $29,26 \%$ \\
3 & $36-45$ & 6 & $14,63 \%$ \\
4 & $46-55$ & 5 & $12,19 \%$ \\
5 & $56-65$ & 7 & $17,1 \%$ \\
6 & $>65$ & 5 & $12,19 \%$ \\
\hline & Total & 41 & $100 \%$ \\
\hline
\end{tabular}

c. Deskripsi Pasien GERD Berdasarkan Jumlah dan Penggolongan Obat

Data penggunaan obat GERD meliputi penggunaan monoterapi dan kombinasi. 
Tabel 3. Data Pasien GERD berdasarkan Jenis dan Penggolongan Obat

\begin{tabular}{|c|c|c|c|}
\hline No & $\begin{array}{l}\text { Penggunaan } \\
\text { Obat GERD }\end{array}$ & $\begin{array}{l}\text { Jumlah } \\
\text { Pasien }\end{array}$ & Persentase \\
\hline 1 & Pantoprazol & 3 & $7,32 \%$ \\
\hline 2 & $\begin{array}{c}\text { Pantoprazol + } \\
\text { Ranitidin }\end{array}$ & 1 & $2,43 \%$ \\
\hline 3 & $\begin{array}{l}\text { Sukralfat + } \\
\text { Pantoprazol }\end{array}$ & 24 & $58,54 \%$ \\
\hline 4 & $\begin{array}{l}\text { Sukralfat + } \\
\text { Ranitidin }\end{array}$ & 3 & $7,32 \%$ \\
\hline 5 & $\begin{array}{l}\text { Sukralfat + } \\
\text { Omeprazol }\end{array}$ & 2 & $4,88 \%$ \\
\hline 6 & $\begin{array}{c}\text { Sukralfat + } \\
\text { Lansoprazol } \\
\text { Sukralfat + }\end{array}$ & 1 & $2,43 \%$ \\
\hline 7 & $\begin{array}{c}\text { Lansoprazol + } \\
\text { Pantoprazol } \\
\text { Sukralfat + }\end{array}$ & 2 & $4,88 \%$ \\
\hline 8 & $\begin{array}{c}\text { Pantoprazol + } \\
\text { Omeprazol } \\
\text { Sukralfat + }\end{array}$ & 2 & $4,88 \%$ \\
\hline 9 & $\begin{array}{c}\text { Pantoprazol + } \\
\text { Ranitidin } \\
\end{array}$ & 3 & $7,32 \%$ \\
\hline & Total & 41 & $100 \%$ \\
\hline
\end{tabular}

\begin{tabular}{cc}
\hline \multicolumn{2}{c}{ Keterangan Penggolongan Obat } \\
\hline Monoterapi & $7,32 \%$ \\
Kombinasi 2 Obat & $75,6 \%$ \\
Kombinasi 3 Obat & $17,03 \%$ \\
\hline Total & $100 \%$ \\
\hline
\end{tabular}

2. Analisis Kualitatif

a. Deskripsi Pasien GERD Berdasarkan Tepat Obat

Tepat Obat adalah ketepatan pemilihan obat yang dilakukan dalam proses pemilihan obat yang harus sesuai dengan indikasi penyakit. Ketepatan obat yang di peroleh sebesar $100 \%$.

Tabel 4. Data Pasien berdasarkan Tepat Obat

\begin{tabular}{|c|c|c|c|}
\hline No & Nama Obat & Indikasi & Ketepatan \\
\hline 1 & Pantoprazol & GERD & 3 \\
\hline 2 & $\begin{array}{c}\text { Pantoprazol + } \\
\text { Ranitidin }\end{array}$ & GERD & 1 \\
\hline 3 & $\begin{array}{l}\text { Sukralfat + } \\
\text { Pantoprazol }\end{array}$ & GERD & 24 \\
\hline 4 & $\begin{array}{l}\text { Sukralfat + } \\
\text { Ranitidin }\end{array}$ & GERD & 3 \\
\hline 5 & $\begin{array}{l}\text { Sukralfat + } \\
\text { Omeprazol }\end{array}$ & GERD & 2 \\
\hline 6 & $\begin{array}{l}\text { Sukralfat + } \\
\text { Lansoprazol } \\
\text { Sukralfat + }\end{array}$ & GERD & 1 \\
\hline 7 & $\begin{array}{c}\text { Lansoprazol + } \\
\text { Pantoprazol } \\
\text { Sukralfat + }\end{array}$ & GERD & 2 \\
\hline 8 & $\begin{array}{c}\text { Pantoprazol + } \\
\text { Omeprazole } \\
\text { Sukralfat + }\end{array}$ & GERD & 2 \\
\hline 9 & $\begin{array}{c}\text { Pantoprazol + } \\
\text { Ranitidin }\end{array}$ & GERD & 3 \\
\hline & Total & & 41 \\
\hline & Persentase & & $100 \%$ \\
\hline
\end{tabular}

b. Deskripsi Pasien GERD Berdasarkan Tepat Dosis

Tepat dosis adalah salah satu tujuan terapeutik untuk mencapai efek yang menguntungkan dengan meminimalisir efek yang merugikan. Data yang dikumpulkan berdasarkan dosis yang tercatat dalam rekam medik pasien. 
Tabel 5. Data Pasien berdasarkan Tepat Dosis

\begin{tabular}{|c|c|c|c|c|c|}
\hline \multirow[b]{2}{*}{ No } & \multirow[b]{2}{*}{$\begin{array}{l}\text { Nama } \\
\text { Obat }\end{array}$} & \multirow{2}{*}{$\begin{array}{l}\text { Dosis } \\
\text { Liter } \\
\text { atur } \\
\text { (mg/ } \\
\text { hari) }\end{array}$} & \multirow{2}{*}{$\begin{array}{c}\text { Dosis } \\
\text { yang } \\
\text { digun } \\
\text { akan } \\
(\mathrm{mg} / \\
\text { hari) }\end{array}$} & \multicolumn{2}{|c|}{ Ketepatan } \\
\hline & & & & Tepat & $\begin{array}{l}\text { Tidak } \\
\text { tepat }\end{array}$ \\
\hline 1 & $\mathrm{P}$ & 40 & 40 & 3 & - \\
\hline 2 & $\mathrm{P}+$ & 40 & 40 & 1 & - \\
\hline 3 & $\begin{array}{l}\mathrm{R} \\
\mathrm{S}+ \\
\mathrm{P}\end{array}$ & $\begin{array}{c}150 \\
4000 \\
40\end{array}$ & $\begin{array}{c}150 \\
4000 \\
40\end{array}$ & 24 & - \\
\hline 4 & $\begin{array}{l}\mathrm{S}+ \\
\mathrm{R}\end{array}$ & $\begin{array}{c}4000 \\
150\end{array}$ & $\begin{array}{c}4000 \\
150\end{array}$ & 3 & - \\
\hline 5 & $\begin{array}{l}\mathrm{S}+ \\
\mathrm{O}\end{array}$ & $\begin{array}{c}4000 \\
20\end{array}$ & $\begin{array}{c}4000 \\
20\end{array}$ & 2 & - \\
\hline 6 & $\begin{array}{l}\mathrm{S}+ \\
\mathrm{L} \\
\mathrm{S}+\end{array}$ & $\begin{array}{c}4000 \\
30 \\
4000\end{array}$ & $\begin{array}{c}3000 \\
30 \\
4000\end{array}$ & - & 1 \\
\hline 7 & $\begin{array}{l}\mathrm{L}+ \\
\mathrm{P} \\
\mathrm{S}+\end{array}$ & $\begin{array}{c}30 \\
40 \\
4000\end{array}$ & $\begin{array}{c}30 \\
40 \\
4000\end{array}$ & 2 & - \\
\hline 8 & $\begin{array}{l}\mathrm{P}+ \\
\mathrm{O} \\
\mathrm{S}+\end{array}$ & $\begin{array}{c}40 \\
20 \\
4000\end{array}$ & $\begin{array}{c}40 \\
20 \\
4000\end{array}$ & 2 & - \\
\hline 9 & $\begin{array}{c}\mathrm{S}+ \\
\mathrm{P}+ \\
\mathrm{R}\end{array}$ & $\begin{array}{c}4000 \\
40 \\
100\end{array}$ & $\begin{array}{c}4000 \\
40 \\
100\end{array}$ & 3 & - \\
\hline & & Total & & 40 & 1 \\
\hline & & sentase & & $97,56 \%$ & $2,44 \%$ \\
\hline
\end{tabular}

c. Deskripsi Pasien GERD Berdasarkan

Tepat Interval Waktu Pemberian

Frekuensi pemberian obat dan pemilihan dosis yang tepat dan disesuaikan dengan kondisi pasien, disebut sebagai tepat interval waktu pemberian.
Tabel 6. Data Pasien berdasarkan Tepat Interval waktu Pemberian

\begin{tabular}{|c|c|c|c|c|c|}
\hline \multirow[b]{2}{*}{ No } & \multirow[b]{2}{*}{$\begin{array}{c}\text { Nama } \\
\text { Obat }\end{array}$} & \multirow{2}{*}{$\begin{array}{c}\text { Interva } \\
\text { I } \\
\text { Pembe } \\
\text { rian } \\
\text { Literat } \\
\text { ur } \\
(\mathrm{mg})\end{array}$} & \multirow{2}{*}{$\begin{array}{c}\text { Interva } \\
\text { l } \\
\text { pembe } \\
\text { rian } \\
\text { yang } \\
\text { diguna } \\
\text { kan } \\
(\mathrm{mg})\end{array}$} & \multicolumn{2}{|c|}{$\begin{array}{c}\text { Ketepata } \\
\text { n }\end{array}$} \\
\hline & & & & $\begin{array}{r}\text { Tepa } \\
\mathbf{t}\end{array}$ & $\begin{array}{l}\text { Tida } \\
\text { k } \\
\text { tepat }\end{array}$ \\
\hline 1 & $\mathrm{P}$ & $1 \times 40$ & $1 \times 40$ & 3 & - \\
\hline & $\mathrm{P}$ & $1 \times 40$ & $1 \times 40$ & & \\
\hline 2 & $\begin{array}{l}+ \\
\mathrm{R}\end{array}$ & $3 \times 50$ & $3 \times 50$ & 1 & - \\
\hline 3 & $\begin{array}{l}\mathrm{S}+ \\
\mathrm{P}\end{array}$ & $\begin{array}{c}4 \times \\
1000 \\
1 \times 40\end{array}$ & $\begin{array}{c}4 \\
\times 1000 \\
1 \times 40\end{array}$ & 24 & - \\
\hline 4 & $\begin{array}{l}\mathrm{S}+ \\
\mathrm{R}\end{array}$ & $\begin{array}{c}4 \times \\
1000 \\
3 \times 50\end{array}$ & $\begin{array}{c}4 \times 100 \\
3 \times 50\end{array}$ & 3 & - \\
\hline 5 & $\begin{array}{r}\mathrm{S}+ \\
\mathrm{O}\end{array}$ & $\begin{array}{c}4 \times 1 \\
1 \times 20\end{array}$ & $\begin{array}{l}4 \times 1 \\
1 \times 20\end{array}$ & 2 & - \\
\hline 6 & $\begin{array}{c}\mathrm{S}+ \\
\mathrm{L}\end{array}$ & $\begin{array}{c}4 \times \\
1000 \\
1 \times 30\end{array}$ & $\begin{array}{c}3 \times \\
1000 \\
1 \times 30\end{array}$ & - & 1 \\
\hline 7 & $\begin{array}{c}\mathrm{S}+ \\
\mathrm{L}+ \\
\mathrm{P}\end{array}$ & $\begin{array}{c}4 \times \\
1000 \\
1 \times 30 \\
1 \times 40\end{array}$ & $\begin{array}{c}4 \times \\
1000 \\
1 \times 30 \\
1 \times 40\end{array}$ & 2 & - \\
\hline 8 & $\begin{array}{l}\mathrm{S}+ \\
\mathrm{P}+ \\
\mathrm{O}\end{array}$ & $\begin{array}{c}4 \times \\
1000 \\
1 \times 40 \\
1 \times 30\end{array}$ & $\begin{array}{c}4 \times \\
1000 \\
1 \times 40 \\
1 \times 30\end{array}$ & 2 & - \\
\hline 9 & $\begin{array}{c}\mathrm{S}+ \\
\mathrm{P}+ \\
\mathrm{R}\end{array}$ & $\begin{array}{c}4 \times \\
1000 \\
1 \times 40 \\
2 \times 50\end{array}$ & $\begin{array}{c}4 \times \\
1000 \\
1 \times 40 \\
2 \times 50\end{array}$ & 3 & - \\
\hline & & Total & & 40 & 1 \\
\hline & & Persenta & & $\begin{array}{l}97,56 \\
\%\end{array}$ & $2,44 \%$ \\
\hline
\end{tabular}


d. Deskripsi Pasien GERD Berdasarkan Tepat Interval Waktu Pemberian

Sifat fisik dan kimia obat, kecepatan respon yang diinginkan, tempat kerja obat yang diinginkan dan kondisi umum pasien merupakan faktor-faktor yang mempengaruhi rute pemberian seperti peroral, topikal, rektal, inhalasi, sublingual, dan parenteral.

Tabel 7. Data Pasien berdasarkan Tepat Rute Pemberian

\begin{tabular}{ccccc}
\hline No & $\begin{array}{c}\text { Nama } \\
\text { Obat }\end{array}$ & $\begin{array}{c}\text { Rute } \\
\text { Pemberian }\end{array}$ & $\begin{array}{c}\text { Ketepa } \\
\text { tan }\end{array}$ & $\begin{array}{c}\text { Persen- } \\
\text { tase }\end{array}$ \\
\hline 1. & P & IV & Tepat & $100 \%$ \\
& & PO & Tepat & $100 \%$ \\
2 & L & PO & Tepat & $100 \%$ \\
3 & O & PO & Tepat & $100 \%$ \\
& & IV & Tepat & $100 \%$ \\
4 & R & IV & Tepat & $100 \%$ \\
5 & S & PO & Tepat & $100 \%$ \\
\hline & & Total & & $100 \%$ \\
\hline
\end{tabular}

Ket :

$\mathrm{P}=$ Pantoprazol

$\mathrm{L}=$ Lansoprazol

$\mathrm{O}=$ Omeprazol

$\mathrm{R}=$ Ranitidin

$\mathrm{S}=$ Sukralfat

Berdasarkan hasil yang didapat dari 41 data rekam medik pasien menjelaskan bahwa persentase pada pasien laki-laki sebesar 46,34\% dan pada pasien perempuan sebesar 53,66\%,dengan demikian dapat disimpulkan bahwa jumlah pasien GERD pada perempuan lebih tinggi dari pasien lakilaki. Data ini menunjukkan bahwa wanita beresiko lebih tinggi terkena GERD daripada pria dan penelitian menunjukkan bahwa tingkat emosional wanita lebih tinggi daripada pria. (Sharma \& Ahuja, 2011). Karakteristik jenis kelamin bukanlah faktor risiko dalam penelitian ini, tetapi dapat dipengaruhi oleh perilaku pasien, seperti tidak menjaga pola makan dan stress, yang semuanya dapat menyebabkan GERD. Kebiasaan ini harus dihindari oleh pasien untuk meningkatkan kualitas hidupnya (Sharma \& Ahuja, 2011).

Klasifikasi berdasarkan usia ini bertujuan untuk membedakan rentang usia tertentu dengan jumlah pasien terbanyak, kemudian dibandingkan dengan data pada literatur. Berdasarkan hasil yang diperoleh menunjukkan bahwa data usia paling tinggi yaitu pada rentang usia 26-35 tahun (dewasa awal) sebesar 29,26\%. Resiko penyakit GERD akan meningkat dengan berbagai kesibukan pekerjaan dan kegiatan lainnya yang sangat berpotensi menimbulkan pola hidup tidak sehat dan stress. Oleh karena itu, angka kejadian GERD paling banyak ditemukan pada usia produktif (Patala, R., dkk., 2021).

Berdasarkan hasil penelitian yang diperoleh, penggunaan obat monoterapi yang digunakan adalah golongan Proton Pump Inhibitor (PPI) yaitu Pantoprazol sebanyak 7,32\%. Terapi PPI merupakan obat terpenting untuk mengobati GERD, menurut 
pengobatan Indonesia. PPI bekerja dengan menghambat sel parietal mensekresi ion $\mathrm{H}+$, karena keunggulan dan keefektifannya, pengobatan GERD harus dimulai dengan PPI.

PPI memiliki paruh waktu yang pendek, tetapi karena pembuatan molekul pompa $\mathrm{H}+/ \mathrm{K}+$ ATPase yang baru membutuhkan waktu setidaknya 18 jam, durasi hambatan terhadap asam dapat bertahan hingga 24 jam. Diperlukan waktu 35 hari terapi untuk mencapai hambatan asam yang optimal karena tidak semua pompa diinaktifkan pada awal terapi. (Panggabean, 2017). Penggunaan PPI sebagai obat pilihan yang lebih efektif dari $\mathrm{H}_{2} \mathrm{RA}$ dan merupakan pilihan obat yang sesuai untuk digunakan pada pasien dengan diagnosa GERD yang sedang sampai yang parah (Dipiro dkk., 2016).

Penggunaan obat GERD kombinasi dua obat diperoleh sebanyak $75,6 \%$, dari kombinasi dua obat ini yang paling banyak digunakan adalah kombinasi dari obat Pantoprazol + sukralfat yaitu sebanyak $58,54 \%$. Hal ini sejalan dengan literatur yang menyatakan bahwa menggunakan kombinasi dua obat PPI lebih efektif, dapat mengurangi komplikasi dan mempercepat pemulihan jika dibandingkan dengan monoterapi (Dipiro dkk., 2016).
Dalam pengobatan GERD, kombinasi tiga obat ditemukan sebesar $17,03 \%$ kasus, dengan Pantoprazol + Sukralfat + Ranitidin terhitung 7,32\% kasus. Ranitidin merupakan golongan antagonis reseptor $\mathrm{H} 2$ yang baik digunakan 30-60 menit sebelum makan. Namun dalam kasus ini ranitidin boleh diberikan setelah makan. Jika digunakan bersamaan dengan sukralfat dapat menurunkan konsentrasi pada ranitidin. Disarankan bahwa ranitidin diberikan satu atau dua jam setelah sukralfat (Rahman A.A., Maulidina, W., dan Kosasih D., 2018).

Selain itu, pada penggunaan terapi bersamaan, seperti golongan PPI + Sukralfat + H2RA tidak di rekomendasikan, karena dapat menambah biaya pengobatan tanpa mendapat keefektifan yang maksimal dari pengobatan tersebut (Dipiro dkk., 2016). Dengan demikian penggunaan obat GERD baik tunggal maupun kombinasi harus disesuaikan dengan tingkat keparahan dan kondisi pasien.

Ketepatan indikasi pengobatan GERD di salah satu Rumah Sakit di Bandung adalah $100 \%$. Hal ini didasarkan pada data yang dikumpulkan dari catatan rekam medis pasien yang sudah sesuai dengan diagnosis.

Berdasarkan hasil penelitian yang diperoleh menunjukkan bahwa penggunaan 
obat GERD yang dibandingkan dengan literatur sudah digunakan tepat dosis sebesar $97,56 \%$ dan hanya $2,44 \%$ yang tidak tepat dosis. Menurut literatur menyebutkan bahwa dosis obat pada sediaan injeksi ranitidine per hari yaitu berada pada rentang $50 \mathrm{mg}-150$ mg (Dipiro dkk., 2016). Pada penggunaan obat ranitidine dalam hasil penelitian yang digunakan yaitu $100 \mathrm{mg}$ per hari, sehingga walaupun yang diberikan hanya 100mg per hari tetap berada dalam rentang terapi tersebut, sehingga dapat dikatakan sudah tepat dosis.

Pada penderita GERD yang penggunaannya stidak tepat dosis adalah pasien yang menggunakan obat sukralfat. Menurut literatur dosis sukralfat yaitu $4 \mathrm{~g}$ per hari (Badan POM, 2014). Pada data penelitian yang didapat penggunaan sukralfat yang diberikan pada pasien GERD hanya $3 \mathrm{~g}$ per hari. Karena dosis yang diperoleh pasien berada di bawah kisaran terapi, maka tidak dapat memberikan respon yang diharapkan dan efek terapi tidak akan tercapai, ketidaktepatan dosis ini disebabkan karena kurangnya dosis yang diberikan.(Santika dkk., 2019).

Berdasarkan data yang diperoleh pada pasien GERD di salah satu Rumah Sakit di Bandung yang dilihat dari ketepatan interval waktu pemberian yaitu sebesar
$97,56 \%$ sudah tepat dan hanya $9,76 \%$ yang tidak tepat dalam interval waktu pemberian. Menurut literatur interval waktu pemberian untuk obat sukralfat yaitu 4 x 1 g (Badan POM, 2014).

Pada data penelitian ini penggunaan sukralfat yang diberikan tidak tepat yaitu hanya 3 x $1 \mathrm{~g}$. Pasien harus diberikan obatobatan yang sesederhana mungkin agar lebih praktis dan mudah diikuti. Frekuensi pemberian obat perhari yang semakin sering maka tingkat ketaatan pasien dalam meminum obat semakin rendah (Kemenkes RI, 2011).

Diketahui bahwa rute pemberian obat yang digunakan di salah satu Rumah Sakit di Bandung 100\% tepat untuk semua jenis obat yang digunakan, berdasarkan data yang dikumpulkan di rumah sakit tersebut. Evaluasi dilakukan dengan menentukan kesesuaian jenis sediaan obat dan rute pemberian obat. Cara pemberian obat yang dipilih harus sesuai dengan obat yang diberikan dan kondisi pasien (Badan POM, 2014).

\section{KESIMPULAN}

Penggunaan obat GERD lebih banyak ditemukan pada pasien perempuan sebesar 53,66\% dibandingkan dengan lakilaki $46,34 \%$, berdasarkan rentang usia paling 
banyak 26-35 tahun sebesar 29,26\%. Obat GERD yang paling banyak digunakan adalah kombinasi dengan 2 obat yaitu Pantoprazol dan Sukralfat sebesar 58,54\%. Penggunaan obat pada pasien GERD sudah rasional dengan persentase penggunaan obat berdasarkan tepat obat $100 \%$, tepat dosis $97,56 \%$, tepat interval waktu pemberian $97,56 \%$ dan tepat rute pemberian $100 \%$.

\section{DAFTAR PUSTAKA}

Badan POM, I. (2014). Informatorium Obat Nasional Indonesia. BPOM. http://pionas.pom.go.id

Bestari, M. B. (2011). Penatalaksanaan Gastroesophageal Reflux Disease ( GERD ). CDK, 38(7), 490-492. https://doi.org/10.32922/jkp.v6i2.81

Darnindro, N., Manurung, A., Mulyana, E., \& Harahap, A. (n.d.).(2018). Prevalence of Gastroesophageal Reflux Disease ( GERD ) in Dyspepsia Patients in Primary Referral Hospital.

The Indonesia Journal Of Gastroenterologi, Hepatology and Digestive Endoscopy, 19.

Dipiro, J.T., Talbert, R.L., Yee, G.C., M., \& G.R., Wells, B, G., dan Posey, L. . (2016). Pharmacotherapy A Phatophysiologic Approach $\left(10^{\text {th }}\right.$ Edition), 289-290. Mc Graw-Hill
Companies United State

El-Serag, H. B., Sweet, S., Winchester, C. C., \& Dent, J. (2014). Update on the epidemiology of gastro-oesophageal reflux disease: A systematic review. Gut, $\quad$ 63(6), 871-880. https://doi.org/10.1136/gutjnl-2012304269

Friyanto, D., Lestari, S., Karawang, P., \& Karawang, P. (2019). Analisis Penggunaan Obat Gastroesophageal Reflux Disease (GERD) Pada Pasien Rawat Jalan di Rumah Sakit Umum Daerah Karawang. http://journal.ubpkarawang.ac.id/index .php/Farmasi/article/view/614 , 240247.

Kemenkes RI. (2011). Modul Penggunaan Obat Rasional. 4-5. Bina Pelayanan Kefarmasian.

Ndraha, S., Oktavius, D., Sumampouw, J. L., Juli, N. N., \& Marcel, R. (2016). Artikel Penelitian Faktor-Faktor yang Berhubungan dengan Keberhasilan Terapi GERD Factors Associated with The Success of GERD Therapy. Journal Kedokteran Meditek, 22(60), $7-13$

http://ejournal.ukrida.ac.id/ojs/index.p hp/Meditek/article/view/1447

Panggabean, M. S. (2017). Tinjauan atas 
Pantoprazole - a Proton Pump

Inhibitor. 44. CDK.journal-258/vol.44 no.(11) th 2017, 831-834.

Patala, R., Tandi, J., \& Ulzmi, N. (2021). Rasionalitas Penggunanaan Obat Pada. Pasien GERD Di Instalasi Rawat Inap Rumah Sakit Umum Anutapura Palu. Journal Of Pharmaceutical Science and Clinical Research, 2021,01, 62-73.

Rahman, A., Maulidina, W., \& Kosasih, E. D. (2018). Gambaran Terapi Awal Pada Pasien Gerd ( Gastroesophageal Initial Therapy For Gerd ( Gastroesophageal Reflux Disease ) Patients In Internist Departement Of Rsud Dr. Soekardjo. 2(6), Jurnal Kesehatan Poltekkes Kemenkes RI Pangkal Pinang, 69-76.

Santika, N. Y., Desnita, R., Yuswar, M. A., Studi, P., Fakultas, F., Universitas, K., Pontianak, T., \& Obat, J. (2019). Evaluasi Penggunaan Obat Tukak Peptik pada Pasien Tukak Peptik di Instalasi Rawat Inap RSUD Sultan Syarif Mohamad Alkadrie Pontianak. Majalah Farmaseutik Vol. 15 No. 1 : 115.

Saputera, M. D., \& Budianto, W. (2017). Diagnosis dan Tatalaksana Gastroesophageal Reflux Disease (
GERD ) di Pusat Pelayanan Kesehatan Primer. Journal Continuing Medical Education 44(5), 329-332.

Sharma, P. K., \& Ahuja, V. (2011). Prevalence, severity, and risk factors of symptomatic gastroesophageal reflux disease among employees of a large hospital in Northern India. Indian J Gastroenterol 30(3), doi: 10.1007/s12664-010-0065-5.128-134. Syam, A. F., Hapsari, F. C. P., \& Makmun, D. (2016). The Prevalence and Risk Factors of GERD among Indonesian Medical Doctors. 20(2), http://journal.ui.ac.id/health.35-40. 